\title{
manomand \\ Abrangências Locais no Jornalismo Online do Tocantins
}

Scopes Places in the Online Journalism of Tocantins, Brazil

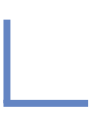

\section{Liana Vidigal Rocha}

Doutora e Mestre em Ciências da Comunicação pela ECA-USP. Jornalista diplomada. Professora-adjunta do curso de Comunicação Social da Universidade Federal do Tocantins (UFT - Palmas). lividigal@uol.com.br

\section{Sérgio Ricardo Soares}

Mestre em Letras (UFPE), graduado em Comunicação Social - Jornalismo (UFPE) e professor assistente do curso de Comunicação Social - Jornalismo (UFT - Palmas). sergior. soares@uol.com.br

\section{Valmir Teixeira Araújo}

Mestre em Desenvolvimento Regional (UFT - Palmas). Graduado em Comunicação Social Jornalismo (UFT - Palmas). valmiraraujo09@hotmail.com

Recebido em 27 de julho de 2014. Aprovado em 11 de setembro de 2014

\section{Resumo}

Este artigo observa empiricamente a representatividade que o Portal CT, site jornalístico independente do Tocantins, dá para a diversidade local. O portal surge como um veículo autônomo e destacado das corporações tradicionais, cujo principal tema explorado está ligado à política local. Foram discutidos assuntos, como glocalização, os estágios do jornalismo on-line e as noções de informação de proximidade. $\mathrm{O}$ trabalho apresenta ainda dados que apontam para a predileção do site por assuntos locais em detrimento de temas nacionais e o destaque para o conteúdo hiperlocalizado relacionado ao município de Palmas.

Palavras-chave: Jornalismo online; cobertura local; Tocantins.

\section{Abstract}

This article empirically observed the representativeness that the Portal CT, an independent journalistic website of the state of Tocantins, Brazil, gives to local diversity. The portal appears as an autonomous vehicle, detached from traditional corporations, whose main explored theme is connected to local politics. Issues were discussed, such as glocalization, the stages of online journalism and the notions of information of proximity. The work also presents data pointing to the predilection of the website for local rather than national issues and the focus on the hiperlocal content related to the city of Palmas.

Keywords: Online Journalism; Local Coverage; Tocantins. 


\section{Introdução}

"O nosso lado é o seu”. Aparentemente apenas mais uma frase de efeito, este é o slogan sustentado pelo Portal CT, um dos principais meios de informação do Tocantins, um estado que revela um mercado midiático centralizado nas mãos de poucos grupos e uma relação intricada com o poder público. A parcialidade nem sempre sutil do jornalismo local, resultado disto, justifica um veículo que se quer independente a usar o lema óbvio da sua função social. Mais além: colocando-se o cursor sobre o slogan da página, abre-se uma caixa de mensagem com os dizeres "O maior site de notícias do Tocantins". A despeito da verificação rigorosa deste título, o Portal CT atribui a si um papel de destaque na cobertura do estado na sua totalidade, estado este estabelecido como uma unidade geopolítica há menos de três décadas, ainda em busca de sua identidade cultural e muito diverso em vários aspectos socioeconômicos.

Se, portanto, é um desafio tratar o Tocantins como uno, buscamos neste texto observar empiricamente a representatividade que o site dá para a diversidade local. A escolha do Portal CT para tal investigação deve-se, além da sua boa audiência e repercussão, ao fato de ser o primeiro site com teor jornalístico (aberto em 2005) sem ligação com as oligarquias midiáticas locais - o que não significa, a priori, imparcialidade. Para esta tarefa, centramos a discussão na editoria Estado, focada, sobretudo, em pautas políticas. Uma amostragem quantitativa foi selecionada - todas as notícias de cinco dias dos meses de junho e julho de 2013 - e submetida a procedimentos de análise de conteúdo. Para tanto, optamos pela classificação prévia das notícias em três categorias: as que tratam de pautas da capital Palmas, as que informam sobre o interior do estado e aquelas que dizem respeito ao Tocantins como um todo.

Emboraessa análise seja breve, procuramos levantar com este texto questões sobre a configuração imaginária do lugar construída pelo jornalismo. Além disso, debater as especificidades da modalidade on-line deste jornalismo possibilita pôr em xeque o próprio conceito de local, que precisa ser revisitado.

\section{Notas históricas do Tocantins}

A reivindicação de um Tocantins como unidade emancipada remonta a séculos. Permanece ainda hoje o cultivo da memória das lutas de Joaquim Teotônio Segurado, militar que, no início do século XIX, liderou uma primeira revolta separatista do norte de Goiás contra a administração desta capitania. Já nesta época, a motivação centrava-se nas más condições econômicas e sociais da região, distante e isolada do centro administrativo goiano, ao sul. A partir da década de 1960, o nome de José Wilson Siqueira Campos passa a despontar

$172 \frac{\text { Comunicação \& Inovação, PPGCOM/USCS }}{\text { v. 15, n. } 29 \text { (171-185) jul-dez } 2014}$ 
capitaneando a campanha da separação. Em 1985, como deputado federal, ele consegue do Ministério do Interior a instituição de um comitê para estudar a separação. O objetivo central é alcançado com a Constrituição de 1988, que determina a divisão de Goiás, garantindo a Siqueira Campos o posto de primeiro governador do Tocantins (CARVALHO, 2002).

O estabelecimento de uma nova unidade da Federação - um novo "lugar" - requisita, para além das justificativas factuais políticas e econômicas, a construção de um imaginário que gere um sentimento de pertencimento às populações outrora goianas e agora tocantinenses. Poderíamos aplicar, em um âmbito estadual, o que Stuart Hall fala sobre as culturas nacionais,

compostas não apenas de instituições culturais, mas também de símbolos e representações. Uma cultura nacional é um discurso - um modo de construir sentidos que influencia e organiza tanto nossas ações quanto a concepção que temos de nós mesmos. (...) Esses sentidos estão contidos nas estórias que são contadas sobre a nação, memórias que conectam seu presente com seu passado e imagens que dela são construídas (2001, pp. 50-51).

Iniciativa simbólica imediata na busca desta identidade foi a alteração do nome de diversos municípios que faziam referência ao Norte de Goiás. Assim, por exemplo, Colinas de Goiás e Miracema do Norte foram rebatizadas como Colinas do Tocantins e Miracema do Tocantins. Em paralelo, ainda hoje prossegue o anseio pela definição da música local, da culinária local etc.

Mas nenhuma ação para firmar a presença do Tocantins no mapa brasileiro foi tão contundente quanto a decisão de construir Palmas. À altura da emancipação, o estado contava com outras cidades de médio porte capacitadas para acolher a capital, como Porto Nacional, Gurupi ou Araguaína. Porém, a opção recaiu sobre surgimento de uma nova cidade, localizada no exato centro do estado, instrumento de desenvolvimento de uma região pouco assistida pelo poder público. Lúcia Moraes (2006) se contrapõe, no entanto, a essa narrativa oficial, identificando em Palmas a culminância de um processo denominado "marcha para o Oeste", uma estratégia para o avanço sobre o interior profundo do país através da implantação de capitais planejadas, modernas em sua aparência urbanística, porém imbuídas de políticas conservadoras e excludentes de ocupação do solo. O fenômeno se iniciaria na década de 1930 com Goiânia e ganharia proporções nacionais com Brasília, nos anos 1960. Três décadas mais tarde, Palmas prolongava a marcha para a fronteira com a Amazônia.

Concebida dentro de preceitos que uniam algo do Modernismo de Brasília ao conceito de cidade-jardim integrada ao meio ambiente, Palmas, logo nos seus primeiros anos, 
foi povoada por massas de imigrantes das mais diversas partes do Brasil, instalados em uma infraestrutura urbana precária que permanece em formação e crescimento até hoje. A população, já tendo ultrapassado 240 mil habitantes em 2012 (segundo dados do IBGE), espalha-se irregularmente em um município com mais de $2000 \mathrm{~km}^{2}$, fazendo que muitas das suas superquadras (com 700 metros de lado) permaneçam ainda vazias, embora convivam com uma arraigada especulação fundiária.

\section{O cenário midiático tocantinense}

Em um lugar com os problemas estruturais típicos da breve cronologia, não surpreende que a mídia tocantinense compartilhe destas limitações. Não obstante, suas características peculiares nos requisitam rascunhar uma História dos principais momentos da comunicação social local. Milton Santos propunha a observação das técnicas - entendidas como intervenções relacionais humanas na natureza - como parâmetro para analisar a idade de um lugar. Nessa sugestão, paira a ideia que, para além da idade científica, cronológica, essas técnicas e seus objetos desvelam um uso específico em cada território, estabelecendo formas de vida e, portanto, modificando a própria existência do território. Se, para o mesmo autor, é "o lugar que atribui às técnicas o princípio de realidade histórica" (SANTOS, 2008, p. 58), arriscamos imaginar a prática midiática, enquanto técnica, como um caso especial, capaz de proporcionar dialeticamente a existência histórica (e imaginária) ao lugar. Este fenômeno é particularmente importante no Tocantins - e, de forma mais enfática, sua capital -, iniciou seu tempo como unidade da Federação em uma época em que os recursos técnico-midiáticos de registro audiovisual estavam em plena disseminação globalizante. Não por outro motivo, são tantos as fotos e os vídeos dos primeiros instantes de Palmas (como por certo nenhuma outra cidade brasileira tenha tido a oportunidade).

Em junho de 2013, o Tocantins passou a contar com sua versão estadual para um dos principais portais noticiosos do Brasil, o G1 (http://g1.globo.com/to/tocantins/). Como de praxe, a entrada no ar pautou a programação da TV Anhanguera, retransmissora local da Rede Globo, do mesmo grupo do G1, sob o discurso festivo de que o estado estaria multiplicando seus veículos. Esse episódio, embora muito pontual, possibilita compreender um traço marcante sobre a realidade midiática local: o caráter de oligopólio da comunicação. Assim, mesmo com um número considerável de veículos de massa, ${ }^{1}$ a mídia local encontra-se distribuída entre poucos grupos empresariais ou famílias.

1 Dados de 2007 do Ministério das Comunicações já indicavam a existência de 111 emissoras comerciais de rádio e TV, 67 rádios comunitárias, duas rádios educativas e uma TV educativa. Disponível em $<$ http://www. mc.gov.br/radiodifusao/dados-de-outorga/23453-dados-por-uf-tocantins>. Acesso em 1 jul 2013.

$174 \frac{\text { Comunicação \& Inovação, PPGCOM/USCS }}{\text { v. 15, n. } 29 \text { (171-185) jul-dez } 2014}$ 
O estudo dos meios de massa tocantinenses, além do mais, precisa sempre levar em conta o cenário de Goiás, cujos veículos já tinham atuação no norte do estado antes da separação. São os casos do Consórcio de Empresas de Radiodifusão e Notícias do Estado de Goiás (Cerne), que retransmitia o sinal da TV Bandeirantes em Gurupi e Araguaína; e da TV Anhanguera, que funcionava em Araguaína desde a década de 1970, retransmitindo a programação da Globo e da Anhanguera de Goiânia.

A presença do poder público no setor se inicia com a criação, em 1989, da Companhia de Comunicação do Estado do Tocantins (Comunicatins), empresa de direito privado (de economia mista), mas com o governo do estado como acionista majoritário. Em 1996, a Comunicatins dá lugar ao Instituto Dom Alano, entidade de direito público, sob a forma de autarquia, que atuaria em conjunto com a Universidade do Tocantins (Unitins) para explorar os serviços de Rádio e TV. No ano seguinte, devido à falta de recursos e objetivando regularizar legalmente o serviço de radiodifusão sob a tutela do Estado, o Instituto é transformado na Fundação Unitins, autarquia com autorização para executar o serviço com fins educativos. Este processo gerou a Rádio Palmas 96,1 FM, que entrou no ar em 2000 em caráter experimental; e a TV Palmas, com transmissões a partir de 2003, que tempos depois passou a se chamar Rede Sat e mais recentemente TVE Tocantins. Ampliando o arco regional, a TV estatal tem sinal captado por 10 municípios maranhenses limítrofes, como Porto Franco (TV Difusora) e Imperatriz (TV Nativa).

No setor privado, a Organização Jaime Câmara (OJC) domina os meios locais. Nascido em Goiânia, o grupo lançou em 1938 o jornal O Popular. Em 1954, a OJC abria a Rádio Anhanguera e, em 1963, iniciava as transmissões da TV Anhanguera. Quarta afiliada da Rede Globo em volume de receita, a TV Anhanguera expandiu-se para o Tocantins, inaugurando sua unidade de Palmas em 1995. Seus principais produtos locais são os telejornais "Bom Dia Tocantins" e "Jornal Anhanguera" $1^{\mathrm{a}}$ e $2^{\mathrm{a}}$ edições (nos moldes do jornalismo local da Globo), o "Jornal do Campo" e o programa "Frutos da Terra", produzido em Goiás. De acordo com a empresa de pesquisa M\&W (2010), somente na capital a emissora possui $62 \%$ da audiência no horário das 6 a $0 \mathrm{~h}$. Outros veículos da OJC atualmente em funcionamento são a Rádio Araguaia FM, a CBN Tocantins, o Jornal do Tocantins (impresso e on-line) e o jornal Daqui Tocantins.

Fundado em 1979 para atender ao norte goiano, O Jornal do Tocantins circulou no formato tabloide até 1981, quando foi fechado sob alegação de inviabilidade econômica e falta de profissionais dispostos a atuar na região. Seu retorno só ocorreria com a criação do estado, ressurgindo em formato standard, inicialmente com 12 páginas. Desde então, firmou-se como o impresso local de maior circulação. Apenas na década de 2010 lançou sua versão on-line, que até o presente é exclusiva para assinantes. Em 2013, o grupo criou 
o Daqui Tocantins, focado no jornalismo popular. Dados sobre outros impressos tocantinenses (incluindo aí as revistas) são bastante insuficientes e imprecisos, já que esses veículos comportam-se de forma sazonal, surgindo, desaparecendo e ressurgindo de acordo com a sucessão de governos (municipais e estadual).

Fora do contexto das grandes empresas de comunicação, uma série de impressos de pequena circulação funciona instavelmente em outras cidades, tais como Porto News e Paralelo 13 (Porto Nacional); Tribuna Tocantins (Gurupi); Correio do Povo (Paraíso); e Voz do Bico (Augustinópolis). Mas a maior parte desses veículos de pequeno porte está mesmo em Palmas. Todos os impressos circulam semanal ou quinzenalmente. O Jornal do Tocantins é a única exceção diária (e, mesmo assim, de terça a domingo).

O painel midiático tocantinense, em quaisquer dos veículos, define-se pela forte dependência de verbas públicas, tendo a publicidade política como carro-chefe. A política, inclusive, é o principal tema das edições. É essa área o universo preferencial de pautas dos blogs e portais de notícia, especialmente influentes no contexto local e objeto de nossa análise mais à frente. Na capital, destacam-se o Portal CT, o site Roberta Tum, o Conexão Tocantins e A Boca do Povo. No interior, os principais veículos noticiosos na internet são o Gurupi Online e A Notícia (Gurupi); Araguaína Notícias e Portal O Norte (Araguaína); Surgiu e Correio do Povo (Paraíso); e Porto News (Porto Nacional).

\section{Do Global ao jornalismo de proximidade}

Historicamente, a ideia de mídia local surge junto com os meios de comunicação. Apesar de europeus e norte-americanos investigarem o assunto desde os anos de 1980, no Brasil, os estudos sobre mídia local/regional vão se consolidar apenas na década seguinte, sintonizando-se à importância do tema, sobretudo porque é inegável a influência dos meios de comunicação de massa na vida do homem moderno, levando informação, cultura e entretenimento.

Os veículos, em um primeiro momento, atingem o público local e, em alguns casos, o público regional. Contudo, é com o desenvolvimento da tecnologia que eles ampliam o seu alcance no sentido das versões nacionais. Já a internet ultrapassa esses parâmetros e desponta como mídia com características globais, alcançando públicos simultaneamente em diferentes pontos do planeta. Com o surgimento das novas mídias, é possível notar um aumento considerável no consumo de informação jornalística. Porém, apesar de a ferramenta proporcionar ao usuário uma conexão com dados de diferentes e longínquas culturas, o que se percebe é um real interesse e valorização da comunicação local.

$176 \frac{\text { Comunicação \& Inovação, PPGCOM/USCS }}{\text { v. 15, n. } 29 \text { (171-185) jul-dez } 2014}$ 
Com o desenvolvimento da globalização da economia e das comunicações, num primeiro momento, chegou-se a pressupor o fim da comunicação local, para em seguida se constatar o contrário: a revalorização da mesma, sua emergência ou consolidação em diferentes contextos e sob múltiplas formas (PeruZzo, 2005).

As novas mídias permitem, principalmente, um encurtamento das distâncias entre as pessoas, as informações e as culturas. O termo globalização torna-se comum e recorrente para explicar o processo de integração socioeconômico, político e cultural que domina o cenário mundial. De acordo com Hall (2001, p. 67), a globalização pode ser entendida como o processo que "atravessa fronteiras nacionais" e que conecta e integra "comunidades e organizações em novas combinações de espaço-tempo", gerando assim novas identificações globais e locais.

Para Santos (2008), uma maior globalidade acaba gerando uma maior individualidade, o que Roland Robertson (2000, p. 251) chama de glocal, isto é, a tendência à globalização com particularidades locais. Deste modo, a glocalização deve adequar-se às necessidades da localidade e não ignorá-las. Para López García (2008), citado por Duarte (2010, p. 4), "nos últimos anos há uma relação tensa, diacrônica e permanente entre o local, o global e o glocal", sendo que quanto mais globalizados, de mais informações locais precisamos. "A identidade passa a ser uma condição ao invés de ser um obstáculo".

A glocalização, por sua vez, é um conceito que facilmente se aplica ao jornalismo on-line. Praticado no novo ambiente comunicacional, a Internet, o jornalismo on-line integra massividade, interatividade e hipertextualidade. Por ser considerado "um meio que permite a comunicação de muitos com muitos em escala global" (CASTELls, 2003, p. 8), a Internet possibilitou, inclusive, a presença de "novos atores e novas práticas do jornalismo", como o uso de plataformas colaborativas (PINTO, 2008, p. 8).

On-line, o processo jornalístico ganhou novos desafios. A interatividade, a multimidialidade e a instantaneidade são apenas algumas das características que podem ser exploradas na rede. As possibilidades de espaço, imediatismo, personalização, e compartilhamento oferecidas pela internet são qualidades que também estão sendo aproveitadas pelo segmento.

Sob o paradigma da interatividade, o jornalismo se renova na cibercultura, constituindo uma nova espécie: a do jornalismo online, que redefine os aspectos de produção, redação, edição e publicação da notícia, circulação, audiência, e a relação com os receptores (BARBOSA, 2001). 
Desde seu surgimento, o jornalismo on-line vem passando por modificações que estimulam a percepção de diferentes estágios. De acordo com Barbosa (2002), a primeira fase pode ser chamada de "reprodução" (ou transposição de conteúdo). Nela, o conteúdo das edições impressas era reproduzido (transposto) de forma sequencial e sem imagens, pois as redações jornalísticas não dispunham de recursos dedicados exclusivamente à edição digital.

Já a segunda fase do jornalismo on-line compreende o momento da "metáfora" (percepção), quando há a introdução do hipertexto e a incorporação de elementos audiovisuais (imagens e áudio), caracterizando-se como a etapa cuja configuração física do jornal digital desprende-se da versão impressa. Tais ações tinham como objetivo explorar as potencialidades da nova mídia. Nessa época, as empresas jornalísticas e os grupos editoriais entenderam que para seus sites "terem visibilidade precisariam ser acessados e, para isso, era necessário ofertar conteúdos para além daquele disponível nas edições impressas". A solução, então, foi introduzir "canais de notícias em tempo real" a fim de motivar e "criar o hábito de leitura da versão online" (BARBOSA, 2002).

A terceira fase é caracterizada pela "incrementação dos conteúdos multimídia", na qual são oferecidos recursos de animação e som, além de interatividade por meio de fóruns, chats e enquetes. Outra particularidade que ganha força é o hipertexto. Antes usado principalmente para organizar o conteúdo, agora ele passa a ser utilizado na "narrativa de fatos" (MielniczuK, 2003, p. 36). Os bancos de dados se tornam também mais um diferencial dos produtos on-line.

Em seguida, observa-se um quarto estágio, ligado à web 2.0, e caracterizado pela prática do jornalismo colaborativo (também chamado de cidadão, participativo e open source), que pode ser entendido como o "ato de um cidadão ou grupo participar ativamente no processo de busca, análise, produção e disseminação de notícias e informações" (GILlmor, 2004). Foram criadas plataformas colaborativas, permitindo, assim, a participação mais efetiva do usuário. Um dos primeiros sites colaborativos foi o "Oh My News", criado em 2000, pelo jornalista sul-coreano Oh Yeon Ho. ${ }^{2}$

Em uma evolução natural, ao observar as recentes mudanças que o jornalismo on-line vem sofrendo, é possível falar em uma quinta fase, fundamentada nas questões da mobilidade, da convergência e do hiperlocalismo. Apesar de ainda estar em processo de estudo, é possível apontar algumas características para esse estágio. Marcada pelo

2 Segundo Brambila (2006), no artigo "Jornalismo Online em OhMyNews", a ideia central era construir um noticiário on-line cujo diferencial dissesse respeito à abertura do acesso e da produção de informação, no sentido de encontrar paridade ou ao menos pluralidade suficiente entre notícias produzidas por veículos conservadores e progressistas.

$178 \frac{\text { Comunicação \& Inovação, PPGCOM/USCS }}{\text { v. 15, n. } 29 \text { (171-185) jul-dez } 2014}$ 
jornalismo desenvolvido para mídias móveis, a quinta etapa tem na inovação e na renovação seus pontos fundamentais para o processo de produção de conteúdo, do formato, da linguagem, da edição, da circulação (e da recirculação), da recepção e do consumo (BArbosa, 2013, p. 33). Para Canavilhas e Santana (2011, p. 54), "os smartphones e tablets estão criando um novo repórter, o denominado mobile journalist, e cidadãos cada vez mais interessados em participar das notícias ou mesmo criar caminhos alternativos à imprensa tradicional".

A integração das mídias acontece a partir da publicação de narrativas jornalísticas multimídia. De acordo com Castilho (2011), tais narrativas permitem a "imersão virtual" do público na notícia no momento que incorpora "o impacto visual, o condicionamento sonoro, a interpretação pelo texto e o compartilhamento de experiências por meio das redes sociais". Junto a isto, o hiperlocalismo é a tendência do jornalismo em explorar temas e discussões de interesse local (região, cidade ou bairro).

É possível afirmar que o jornalismo na Internet, ao longo de sua evolução, possibilitou transformações, fazendo que sua consolidação acontecesse de forma mais rápida se comparada a outros modelos. Grandes empresas jornalísticas têm investido, sobretudo, na mobilidade e na convergência como forma de se consolidarem e expandirem sua audiência no mercado digital. Em contrapartida, os sites jornalísticos independentes (aqueles que não estão ligados a conglomerados de comunicação e/ou empresas de grande porte da área), na impossibilidade de concorrer com os grandes veículos, apostam no jornalismo de proximidade para manter e, quem sabe, ampliar sua audiência.

De acordo com Duarte (2010, p. 4), "falar de proximidade passa, obrigatoriamente, por falar do território e dos destinatários das mensagens". A proximidade é uma peculiaridade própria do jornalismo, não importando o veículo ser de natureza regional ou local. Ressaltemos que a relação não deve acontecer somente no âmbito mídia-comunidade, mas também da comunidade para com a mídia. No caso da Internet, a interatividade e a participação tornam essa tarefa mais fácil, visto que o papel do jornalismo de proximidade é atualizar e contextualizar a cultural local, servindo de contraponto às publicações nacionais e internacionais. $\mathrm{O}$ objetivo é ser útil à sociedade e, consequentemente, à região na qual atua.

Camponez (2011, pp. 39-40) revela que o jornalismo de proximidade, por ser direcionado a um público bem específico, deveria ser "mais humano e mais verdadeiramente social", tendo a informação um carácter mais plural devido à oportunidade de melhor representar a sociedade na qual se encontra. Para o autor, o jornalista local é um "generalista sobre as questões de sua região", além de atuar como um "narrador do cotidiano repetitivo". O que não chega a ser considerado um aspecto negativo, visto que a 
participação da sociedade em questão torna-se mais efetiva, proporcionando ao jornalista conhecer as "mentalidades, hábitos, modos de viver, níveis de vida, preocupações culturais e sociais" da sua comunidade geográfica.

É justamente um desses casos que descreveremos a seguir, buscando observar as consequências de representação geopolítica que o jornalismo on-line, na sua forma e nos seus usos contemporâneos - e também imbuído das características contextuais próprias do fazer midiático tocantinense -, impinge ao imaginário sobre o lugar.

\section{Portal CT: cobertura local e regional}

Como na mídia de cobertura global, um desafio da cobertura local é também a representação geopolítica, tendo em vista a existência do hiperlocal (como uma cidade ou um bairro), dentro de uma conjuntura midiática regional (focada em um estado ou região). Para melhor exemplificar esta discussão, apresenta-se a seguir um estudo quantitativo, sobre a representação do lugar Tocantins no noticiário produzido pelo Portal CT.

Primeiramente, cabe uma descrição desse objeto de estudo. De acordo com as informações apresentadas nas páginas do próprio Portal, o projeto que possibilitou sua criação foi iniciado em março de 2005 pelo jornalista Cleber Toledo. Na ocasião, Toledo, que era editor de política no Jornal do Tocantins e professor universitário no curso de Jornalismo de uma universidade particular, criou sozinho o blog clebertoledo.blog. br. A cobertura acontecia de forma estática, com atualização realizada uma vez ao dia. O conteúdo era analítico e focado nos bastidores da política tocantinense, posteriormente se desdobrando aos demais acontecimentos do estado. Ainda no período do blog, Toledo passou a realizar atualização em tempo real.

Em 2006, o projeto do blog passa por alterações e se transforma em um site clebertoledo.com.br. Na ocasião, a equipe de profissionais é ampliada e há uma reforma do projeto editorial, incluindo novas editorias, como Estado e Polícia, ainda que Política permaneça como destaque. $O$ tom das publicações deixa de ser exclusivamente analítico e passa também aos conteúdos noticiosos. O surgimento do site se deu em um ano eleitoral, quando ocorreu a disputa pelos cargos de deputado estadual e federal, senador, governador e presidente. Logo, o veículo realizou a primeira cobertura em tempo real - por meio da internet - da campanha e da apuração dos resultados de uma eleição na História do Tocantins.

Em 2007, o projeto do veículo passa por uma nova reformulação com a criação do Portal Cleber Toledo, disponibilizando material jornalístico em texto, vídeo e áudio. Política permaneceu a editoria central, ainda mais com as eleições municipais de 2008.

$180 \frac{\text { Comunicação \& Inovação, PPGCOM/USCS }}{\text { v. 15, n. } 29 \text { (171-185) jul-dez } 2014}$ 
Por outro lado, segundo Cleber Toledo, o projeto de utilização de vídeo e áudio não obteve o êxito esperado e o Portal resumiu-se às publicações de textos e fotos. O projeto de expansão do Portal rendeu prejuízos financeiros, pois, como diz o jornalista, também diretor geral do veículo, "o mercado não investiu como era esperado".

No ano de 2009, o Portal Cleber Toledo passa a ser denominado como Portal CT e atinge a marca de 1,3 milhão de visitas ao mês e 15 milhões de acessos ao ano, destacando-se como, no estado, o maior e mais visitado veículo na Internet, conforme dados divulgados pelo próprio Portal. Em 2010, em novo pleito eleitoral, o Portal CT atingiu um novo recorde: 20 milhões de acesso no ano.

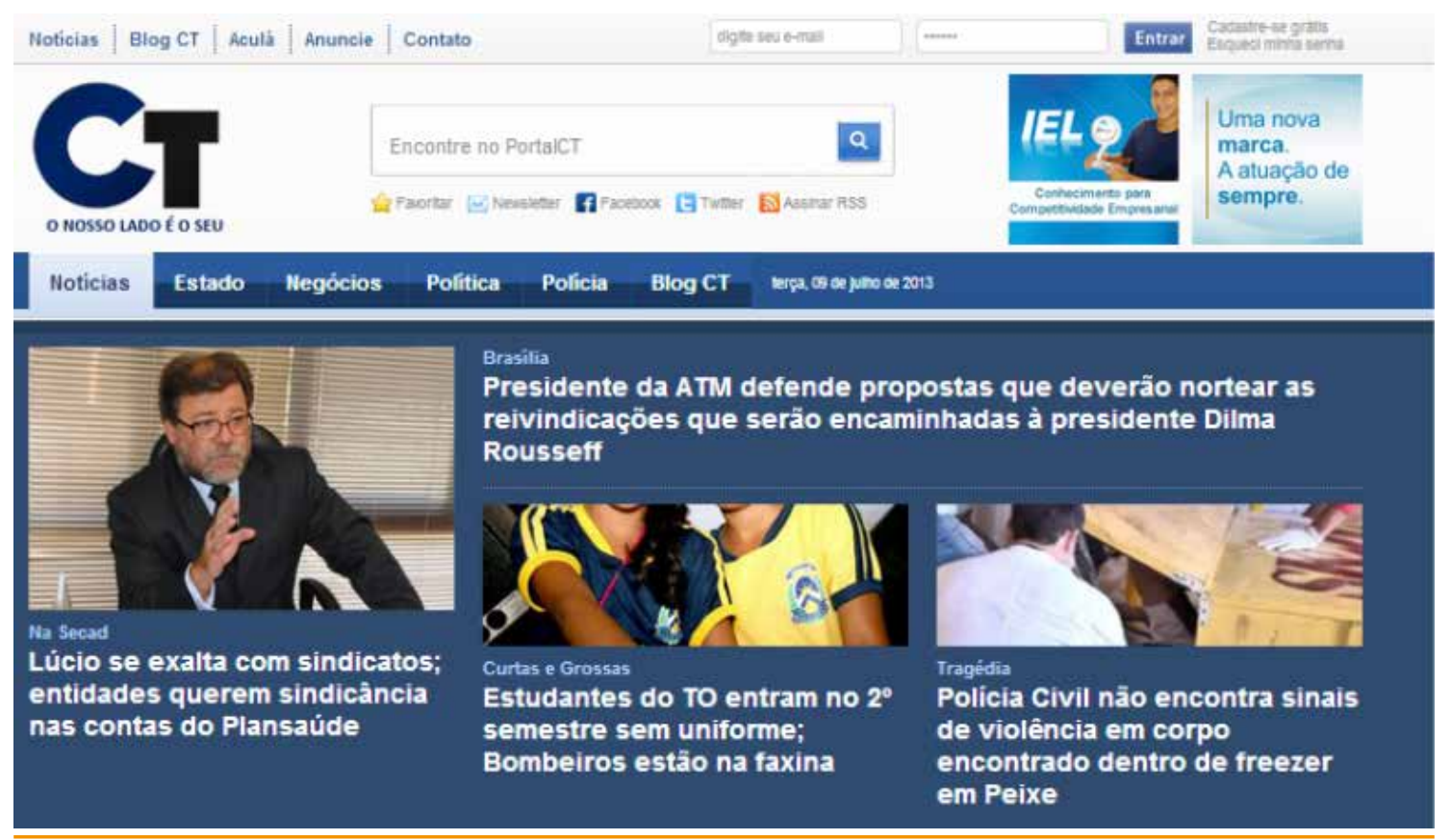

Figura 1: Home Page do Portal CT

Fonte: http://www.portalct.com.br/

O próprio Portal anuncia ser visitado por usuários dos 139 municípios tocantinenses (número total de municípios do estado, aliás). Sua sede fica, desde a fundação, em Palmas, apesar de focar nos assuntos de abrangência regional (estadual). Conta ainda com a parceria do blog Araguaína OnTime, instalado em Araguaína, segundo município em população do Tocantins.

A trajetória seguida por Toledo na criação de um veículo de comunicação independente a partir de um blog se tornou inspiração para outros sites e portais do estado. É importante destacar que este caminho, que diverge dos grandes portais de notícias do Brasil, como o Grupo Folha de S. Paulo e as Organizações Globo, grandes e tradicionais empresas jornalísticas que investiram no mercado digital e consolidaram, respectivamente, 
o Portal UOL e o Globo.com como destaques nacionais em visibilidade e audiência. A aposta do conteúdo de proximidade, focado em assuntos do Estado, pode ser considerado como um dos fatos que possibilitou o Portal CT e outros veículos locais a manter a concorrência com veículos tradicionais e financeiramente consolidados, como o Jornal do Tocantins.

O foco do Portal CT em divulgar notícias relacionadas com o interesse estadual é confirmado pelo diretor do veículo. Contudo, ele admite que, por uma questão de audiência, assuntos de interesse local (como questões relacionadas a um município específico), também recebem cobertura do Portal. As matérias relacionadas ao estado e aos municípios tocantinenses são divulgadas na editoria Estado. Além desta, estão atualmente no ar as editorias Negócios, Política, Polícia e Blog CT.

A partir da discussão aqui esboçada sobre mídia e representação geopolítica e pela proposta do Portal CT em propor uma cobertura de abrangência estadual, pesquisou-se o noticiário da editoria Estado do portal com a finalidade de mensurar o quantitativo de material divulgado, classificando-o em pautas relacionadas com o Tocantins de maneira ampla, pautas sobre o município de Palmas e aquelas sobre os demais municípios do estado.

A pesquisa para o estudo de caso foi realizada a partir da totalidade de matérias publicadas na editoria de Estado do Portal CT, em cinco dias da semana diferentes, dos meses de junho e julho de 2013: 03 de junho (segunda-feira), 11 de junho (terça-feira), 19 de junho (quarta-feira), 27 de junho (quinta-feira) e 5 de julho (sexta-feira). 94 matérias compuseram a amostra, sendo 24 no primeiro dia da pesquisa, 19 no segundo, 14 no terceiro, 21 no quarto e 16 no último dia.

Em conformidade com a tabela abaixo, a maior parte das matérias publicadas na editoria de Estado do Portal CT no período observado relaciona-se ao município de Palmas - 48 publicações (51\%). As publicações que tratam genericamente do estado apareceram em segundo lugar, com 33 matérias - o que representa $35 \%$. Por fim, foram publicadas 13 matérias sobre alguns dos 138 municípios restantes - apenas 14\%.

Tabela 1 - Foco de matérias da editoria Estado do Portal CT

\begin{tabular}{lcccc} 
Data da pesquisa & Palmas & Interior & Estado & Total \\
\hline 03 de junho & 6 & 4 & 14 & 24 \\
\hline 11 de junho & 14 & 2 & 3 & 19 \\
\hline 19 de junho & 6 & 4 & 4 & 14 \\
\hline 27 de junho & 11 & 2 & 4 & 21 \\
\hline 05 de julho & 11 & 1 & $33(35 \%)$ & 94 \\
\hline Total & $48(51 \%)$ & $13(14 \%)$ & 46 \\
\hline
\end{tabular}


A partir destes dados pontuais, torna-se razoável questionar o foco do veículo como estadual, ao invés de local. Todavia, é importante destacar que o noticiário local relacionado a Palmas - não pode ser excluído da abrangência regional (estadual). Logo, acentua-se e exemplifica-se a discussão sobre a dificuldade de estabelecimento das dimensões globais, regionais e locais.

Ao verificar a dimensão geopolítica das publicações da editoria em questão, a desproporção quantitativa da representação torna-se ainda mais evidente. Excluindo-se as publicações relacionadas ao estado de maneira geral e contabilizando apenas o noticiário exclusivamente local, isto é, relacionado a algum município, encontramos 61 publicações, ou seja, $65 \%$ das publicações da editoria Estado possuem um caráter local. Este dado demonstra o espaço do jornalismo local, isto é, de proximidade no jornalismo on-line. Destas 61 publicações locais, 51 (84\%) são relacionadas a apenas um dos 139 municípios tocantinenses - Palmas - um número considerável, ainda que se trate da capital. Logo depois aparece Araguaína, com cinco publicações (8\%) e Gurupi, com duas matérias (cerca de 3\%). Há ainda citação a outros seis municípios: Paraíso do Tocantins, Porto Nacional, Araguatins, Pedro Afonso, Santa Fé do Araguaia e Ponte Alta do Tocantins.

Em suma, constata-se uma inegável desproporção na representação dos municípios tocantinenses na editoria. Apesar da proposta do Portal ser o alcance estadual, a abrangência local destaca-se. Algumas questões, como o fato do Portal CT ter sede em Palmas e não contar com estruturas fixas no interior podem contribuir, por outro lado, para a compreensão da realidade apresentada no caso.

\section{Considerações finais}

No decorrer deste texto, foram reunidas informações sobre a história do Tocantins e o percurso dos meios de comunicação no estado. Além disso, temas do jornalismo on-line, informação de proximidade e globalização auxiliaram no embasamento teórico da pesquisa com o intuito de dar sustentação aos exemplos apresentados.

A partir desses dados, foi possível perceber, em um primeiro momento, que a glocalização (globalização com características locais) não deve ignorar as especificidades da localidade, mas sim adaptá-las para sua realidade. Em seguida, observou-se que os sites jornalísticos considerados independentes investem na informação de proximidade na tentativa de manter e ampliar sua audiência, visto que, na maioria das vezes, apresentam dificuldades para concorrer com os grandes veículos.

$\mathrm{O}$ estudo de caso realizado neste trabalho possibilitou confirmar a necessidade dos sites jornalísticos independentes, como o Portal CT, de investir em conteúdos de 
proximidade, como forma de garantir audiência. Por sua vez, como demonstraram os números analisados, o conteúdo de proximidade do Portal CT privilegiou mais assuntos locais (de interesse específico dos municípios), que necessariamente os assuntos regionais (de interesse do Tocantins).

Por fim, ganhou relevância na pesquisa o destaque para o conteúdo local, relacionado ao município de Palmas, em detrimento dos conteúdos relacionados aos demais municípios do estado. Embora justificada por vários fatores, esta ênfase não é plenamente apoiada pela História local - em que Palmas é, digamos, um fato recente e ainda a se resolver no imaginário cultural. Portanto, "o maior site de notícias do Tocantins" revela-se uma contribuição no estabelecimento de uma certa distorção jornalística, cuja atenção parece "estar ao lado" dos centros políticos, que tendem a monopolizar o poder de representação da comunicação noticiosa.

\section{Referências}

Barbosa, Suzana. "Jornalismo Online: dos sites noticiosos aos portais locais". In: Congresso Brasileiro de Ciências da Comunicação, 24, 2001, Campo Grande, Anais... Campo Grande: Universidade Federal do Mato Grosso do Sul, 2001.

- A informação de proximidade no jornalismo online. Revista Contracampo 7, Dossiê Tecnologias: Niterói: Instituto de Arte e Comunicação Social; v.7, 47-69, $2^{\circ}$ sem/2002. Disponível em: <http://bocc.ubi.pt/pag/barbosa-suzana-proximidade-online.pdf $>$. Acesso em 1 jul. 2013.

. "Jornalismo convergente e continuum multimídia na quinta geração do jornalismo nas redes digitais”. In: Canavilhas, João (org). Notícias e Mobilidade - jornalismo na era dos dispositivos móveis. Covilhã: UBI, LabCom, 2013.

Brambilla, Ana Maria. Jornalismo Online em OhMyNews. Disponível em: <http://culturaderede.pbworks. com/f/genealogia_do_ohmynews.pdf>.Acesso em 1 jul. 2013.

Camponez, Carlos. "Jornalismo Regional: proximidade e distanciações. Linhas de reflexão sobre uma ética da proximidade do jornalismo". In: CORREIA, João Carlos (org.). Ágora - Jornalismo de proximidade: limites, desafios e oportunidades. Covilhã, UBI: LabCom, 2011.

Canavilhas, João \& Santana, Douglas Cavallari. Jornalismo para plataformas móveis de 2008 a 2011: da autonomia à emancipação. Revista Líbero - São Paulo - v. 14, n. 28, p. 53-66, dez. de 2011. Disponível em: <http://www.casperlibero.edu.br/rep_arquivos/2011/12/12/1323717850.pdf>. Acesso em: 2 jul. 2013.

Carvalho, Luiz de. Testemunho da História de Vila Boa (Goyaz) a Palmas (Tocantins). Palmas: Ed. do autor, 2002.

$184 \frac{\text { Comunicação \& Inovação, PPGCOM/USCS }}{\text { v. 15, n. } 29 \text { (171-185) jul-dez } 2014}$ 
CAStells, Manuel. A Galáxia da Internet: reflexões sobre a internet, os negócios e a sociedade. Rio de Janeiro: Jorge Zahar, 2003.

CAstilho, Carlos. Jornalismo Multimidia Online desafia rotinas e valores da profissão e da sociedade. Observatório da Imprensa, maio de 2011. Disponível em: <http://www.observatoriodaimprensa. com.br/posts/view/jornalismo-multimidia-online-desafia-rotinas-e-valoresda-profissao-e-da-sociedade>. Acesso em 2 jul. 2013.

DuARTE, Ângela Filipe Alves. Jornalismo de proximidade: o papel informativo da imprensa local. Ensaio para o seminário Questões Contemporâneas do Jornalismo. Portugal: Universidade Nova de Lisboa, maio de 2010.

Gillmor, Dan. We the Media: - Grassroots Journalism by the people, for the people. O'Reilly, 2004.

HALL, Stuart. A identidade cultural na pós-modernidade. Rio de Janeiro: DP\&A, 2001.

MieLNICZUK, Luciana. Jornalismo na web: uma contribuição para o estudo do formato da notícia na escrita hipertextual. 2003. 246p. Tese (Doutorado) - Universidade Federal da Bahia, Faculdade de Comunicação, Salvador. Disponível em: <http://www.facom.ufba.br/jol/producao_teses.htm> Acesso em: 1 jul. 2013.

Moraes, Lúcia Maria. A segregação planejada: Goiânia, Brasília e Palmas. Goiânia: Ed. da UCG, 2006.

Peruzzo, Cicilia M. Krohling. Mídia regional e local: aspectos conceituais e tendências. Comunicação e Sociedade. São Bernardo do Campo: Póscom-Umesp, Ano 26, n. 43, p. 67-84, 1º sem. 2005.

Pinto, Manuel. Jornalismo: Mudanças na Profissão, Mudanças na Formação. Seminário organizado pelo Centro de Estudos de Comunicação e Sociedade, Universidade do Minho, Portugal, 2008.

Robertson, Roland. Globalização: teoria social e cultura global. Petrópolis: Vozes, 2000.

SANTos, Milton. A natureza do espaço: técnica e tempo, razão e emoção. São Paulo: Edusp, 2008. 